The book is very readable, well produced and free from spelling errors (I learned a new word: deigma). There are first rate indexes. Despite my criticisms, students of the group will want to possess the book, and those who use Myxomycetes as research tools, while less likely to want to buy it, will want it available in easy reach.

David Park

\section{WELSH FERNS}

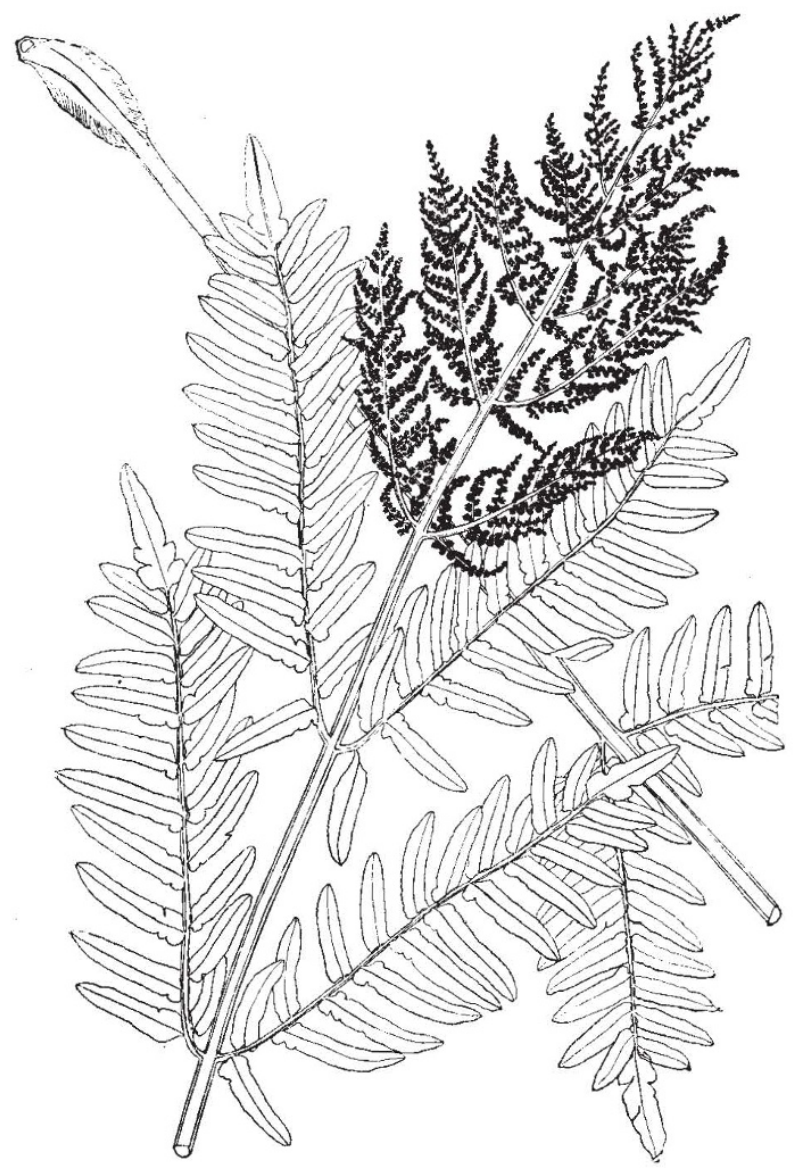

Royal fern (Osmunda regalis) found in bogs, marshy ground, marshy copses and borders of damp woods, and recorded from every county in Wales, although now rare and extinct in many of its former localities. From the fifth edition of Welsh Ferns, Clubmosses, Quillworts and Horsetails: A Descriptive Handbook, by H. A. Hyde and A. E. Wade, revised and expanded by S. G. Harrison (National Museum of Wales: Cardiff, 1969, 25s).

\section{EUROPEAN BOTANY}

\section{Flora Europaea}

Vol. 2: Rosaceae to Umbelliferae. Edited by T. G. Tutin, V. H. Heywood, N. A. Burges, D. M. Moore, D. H Valentine, S. M. Walters and D. A. Webb. Pp. xxvii + 455. (Cambridge University Press: London, December 1968.) $147 s ; \$ 23.50$.

Noт only politically and economically is Britain anxious to get into Europe; it appears that British botanists show a similar desire, and their efforts have met with much greater success. The tangible result of this venture to date is two volumes of the projected four volume Flora Europaea produced by a predominantly British editorial committee. The first volume appeared in 1964, and little more than four years later we have the second which deals with the Rosaceae, Legurninosae and Umbelliferae, as well as forty-seven smaller families.

One cannot but admire the consistency of production in a work to which more than fifty botanists from all over Europe have contributed. The layout, scope and terminology show a uniformity throughout for which the editors must be congratulated. In taxonomic treatment, an unavoidable unevenness is apparent in the first volume. but in the second, whether by chance or design, a fairly consistently conservative view of most genera seems to have been taken. Cornus sensu lato and Epilobium sensu lato are reinstated, undoubtedly to many people's satisfaction. In the Genisteac, however, many of us will have to adjust our generic concepts to some extent, although the new scheme has much to recommend it. I was sorry to see Retama Boiss. disappear in favour of the unfamiliar Lygos Adans.

One particularly interesting feature of this volume is the treatment of apomictic genera in the Rosaceac. There can be no roally satisfactory solution for dealing with such multiplex groups as Rubus, Sorbus and Alchemilla. The method used here has been to describe and key a selection of usually more widespread species which represent the range in variation-seventy-five species in Rubus. eighteen in Sorbus and one hundred and eighteen in Alchemilla -and after each of these circle-species to list the other related species mentioned in the standard national floras, giving thoir distributions.

The past treatments of these genera in different parts of Europe have been uneven, and this unevenness is inevitably reflected in the accounts in this volume. 'The results scem clear and concise, which is perhaps misleading, and my attempts at the Rubus key, while surprisingly successful in places, showed that it is of chiefly theoretical interest rather than of practical value as a means of identification. In Alchemilla, where apomixis poses fewer intractable problems, the key seemed more successful.

Nevertheless, these accounts represent a very real contribution to a general understanding of these genera, and should encourage more effort in their identification. By attempting to describe the distribution and variation of parts of the wood, in spite of the trees, the authors make it possible to gain a greater insight of the group as a whole, outside the requirements of conventional taxonomy.

To British botanists, the account of Rosa will seem unfamiliar, as it assigns to Britain various species which fow will have heard of, and one might be tempted to question their validity. But here, as everywhere else, the account needs testing thoroughly before any judgment can be made.

The Umbelliferae, with which the volume closes, present rather different problems. To the uninitiated, the genera all seem to be rather similar and most keys rely heavily on fruit characters. To name an unfamiliar umbellifer without ripe fruit can often prove very difficult, and therefore the present key, in which non-fruiting characters have been used wherever possible, should be particularly valuable.

There appear to be very few small errors in the text, and only a few larger ones drew my attention. Rhamnus pumilus Turra and Buxus balearica Lam. are incorrectly described as endemics, both being reported from North Africa, as is Potentilla alchimilloides Lapeyr. In this instance, however, one is left wondering whether this is because of omission or taxonomic decision.

Floras seem to fall into three categories. On the one hand are those which are little more than catalogues giving distribution and, on the other hand, are those which are exhaustive in concept and usually are published in small parts. Those in the latter category are rarely completed, as botanists' interests change and their enthusiasm wanes after the initial burst of energy.

Taxonomists, however, have a duty to provide complete taxonomic accounts of an area, in which emphasis is on utility to others such as ecologists, agriculturists 